\title{
Morphological identification of parasitic nematode infective larvae of small ruminants and cattle: A practical lab guide
}

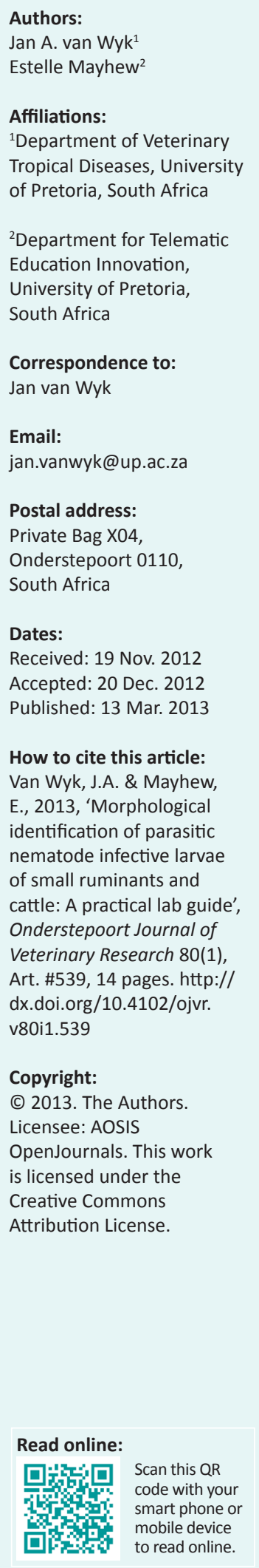

In 2004, a new concept was introduced for simplifying identification of larvae of the common nematodes of cattle, sheep and goats that comprises estimates of the lengths of the sheath tail extensions of infective third-stage larvae $\left(\mathrm{L}_{3}\right)$ of each genus and/or species to that of Trichostrongylus spp., instead of having to be dependent only on measurements in micrometre. For example, if the mean length of the sheath tail extension (the extension of the sheath caudad, beyond the caudal tip of the larva) of Trichostrongylus colubriformis and Trichostrongylus axei is assumed to be ' $\mathrm{X}$ ', then that of Haemonchus contortus is $2.0-2.7$ ' $\mathrm{X}^{\prime}$ - a difference that is not difficult to estimate. An additional new approach suggested now, particularly for $\mathrm{L}_{3}$ of species and/or genera difficult to differentiate (such as Chabertia ovina and Oesophagostomum columbianum), is to estimate the proportion of the larval sheath tail extension comprising a terminal thin, whip-like filament. For the experienced person, it is seldom necessary to measure more than one or two sheath tail extensions of $\mathrm{L}_{3}$ in a mixed culture, because the identity of most of the remaining $\mathrm{L}_{3}$ can thereafter be estimated in relation to those measured, without having to take further measurements. The aim of this article was to present the novel approach in the form of a working guide for routine use in the laboratory. To facilitate identification, figures and a separate organogram for each of small ruminants and cattle have been added to illustrate the distinguishing features of the common $\mathrm{L}_{3}$.

\section{Introduction}

Based on a review by Van Wyk, Cabaret and Michael (2004) and helminthological literature over nine decades, the present article is aimed, through a novel approach and illustrations drawn to scale, at facilitating the morphological identification of infective nematode larvae $\left(\mathrm{L}_{3}\right)$ of the common nematodes of small ruminants and cattle.

Diagnosis of parasitic nematode infections of ruminants, both qualitative and quantitative, is largely still dependent on relatively inaccurate methods such as faecal worm egg counts and accompanying larva identification, without which no indication can be obtained of the identities of most of the common worm genera, excepting for those genera with morphologically distinct ova, for example Strongyloides papillosus, Nematodirus spp. and Trichuris spp. In contrast, ova of Ostertagia, Teladorsagia, Trichostrongylus, Oesophagostomum, Chabertia spp. and, to some extent, Cooperia, Bunostomum and Gaigeria spp. are either difficult or impossible to differentiate without measurements and computations that are, as yet, impractical for routine use. Although some progress has been made with computerised identification (Christie \& Jackson 1982), this has not been developed for general use.

Large differences in the pathogenicity of the common worm genera make it essential to know which nematode genera are responsible for cases of morbidity of animals. At present, the only practical method available for routine laboratory estimation of the proportions of the worm genera present in the living animal, is to identify the larvae that are found in fresh faeces (mostly lungworm larvae) or those that develop in faecal cultures (gastrointestinal nematodes). However, it is often only the experienced person who can identify the larvae with a high degree of accuracy and few such persons remain for training the inexperienced. For many of the nematode genera, distinguishing features such as the shape of the cranial extremity (the head) of the larva are practically indistinguishable to all but the practised eye. Measuring first-stage larvae $\left(\mathrm{L}_{1}\right)$ of protostrongylids and the $\mathrm{L}_{3}$ of strongyles, or the length of the sheath tail extension (STE) (from the caudal tip of the larva to the tip of the STE - ' $\mathrm{c}$ ' in Figure 1) can aid identification, but, being too time-consuming, it is not practical to measure each larva during routine differential diagnosis.

In this article, a simplified, better-structured method is described for differentiating the $\mathrm{L}_{1}$ of various genera of protostrongylids and the $\mathrm{L}_{3}$ of strongyles from one another. Whilst some 
conventional characteristics are still used for identification, the novel approach principally comprises a comparison of the lengths of the STEs of $\mathrm{L}_{3}$ of the unknown identity to those of Trichostrongylus axei and Trichostrongylus colubriformis and estimating the proportion (if any) which comprises a whiplike filament ('d' in Figure 1).

\section{Materials and methods}

Only some methods which are not more or less universal laboratory proceedings are included below.

\section{Faecal cultures and harvesting of infective larvae}

There are numerous different methods for preparing faecal cultures. However, in this laboratory they are prepared as follows by a modification of the technique of Roberts and O'Sullivan (1950), as described by Reinecke (1973) for all but the various lungworm and Nematodirus species. In short, sheep faecal pellets are thoroughly crumbled before being mixed with sufficient vermiculite chips to yield a crumbly mixture which is lightly compacted, using non-porous stampers, to a depth of about $5 \mathrm{~cm}$ in wide-mouthed glass jars of approximately $1 \mathrm{~L}$ capacity. A hole is left in the centre of the culture by holding a stamper vertically in the centre of the jar whilst the mixture is lightly compacted around it. The culture is moistened sufficiently to ensure that it does not dry out whilst being incubated, but without it becoming water-logged. Thereafter, the jar is incubated in the dark at $26{ }^{\circ} \mathrm{C}-28{ }^{\circ} \mathrm{C}$ for $5-7$ days, during which time it is checked periodically and moistened if necessary. Note that, as discussed by Van Wyk et al. (2004), the length of both the larva and its STE may vary in relation to the amount of moisture in the culture medium (Rossanigo \& Gruner 1996), so this needs to be standardised for consistent results.

After the 7-day period of incubation of the culture, the inside of the jar is sprayed lightly with water from a wash bottle before being placed in bright light that stimulates the $\mathrm{L}_{3}$ to migrate up the inner surfaces of the vessel's walls. The culture is harvested repeatedly over several days by holding the jar at a slant with the mouth pointing downwards and then spraying the inner walls with a wash bottle and allowing the larval suspension to drain into suitable containers.

As Gaigeria pachyscelis and Bunostomum phlebotomum do not migrate readily up the walls of the culture jars, they are harvested by filling the culture jar with water, allowing it to stand for a few minutes to allow the air to escape from the culture, adding water to the jar until the water meniscus protrudes above the lip of the jar, placing an overturned Petri

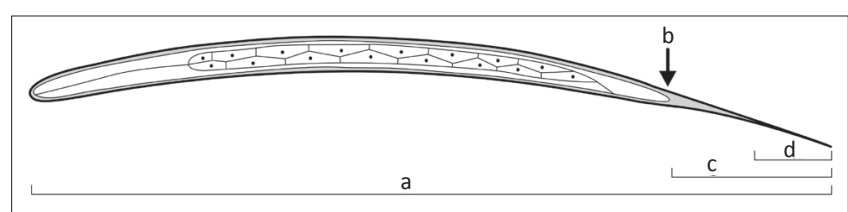

Source: Drawn from Borgsteede, F.H.M. \& Hendriks, J., 1974, 'Identification of infective larvae of gastrointestinal nematodes in cattle', Tijdschrift Diergeneeskunde 99, 103-113. FIGURE 1: Diagram of a nematode infective larva, depicting (a) total length, (b) tip of larva tail, (c) sheath tail extension and (d) filament. dish over the mouth of the jar and keeping the Petri dish in position whilst the jar is inverted (Borgsteede \& Hendriks 1974; Eckert 1960). Water is then added to the Petri dish and the rim of the jar is lifted slightly from the bottom of the dish on one side by slipping two glass microscope slides under it. The preparation is left for a few hours for $\mathrm{L}_{3}$ to migrate into the water and to settle, before the water in the Petri dish is removed with a pipette for larval identification and counting.

Because Nematodirus spp. ova need up to 14 days to hatch, fungal overgrowth commonly makes the above culture method unsuitable for members of this genus. Thus the ova are initially concentrated in relatively little faecal suspension by sieving through a combination of sieves with apertures of different sizes. So-called Visser sieves (a set consisting of three tubular sieves fitting one into the other) (Malan \& Visser 1993) are ideal, with sieve openings of about $200 \mu \mathrm{m}$ in the inner tube, $150 \mu \mathrm{m}$ in the middle and $38 \mu \mathrm{m}-60 \mu \mathrm{m}$ apertures in the outer tube sieve. The latter sieve is capped at the bottom to accumulate the contents in about $20 \mathrm{~mL}$ of water, whilst a tap is provided in the cap for drainage. The faecal sample is placed in the inner tube sieve before being thoroughly washed with a rosette of spray using an adjustable garden spray on a hose, with the effluent passing through all three tubes. The inner tube sieve is then removed and the contents of the middle tube washed similarly before it is removed in turn and the process repeated for the outer tube. Nematodirus spp. and Marshallagia marshalli ova are retained in suspension in the inner tube and are cleaned further by progressive removal of the faecal particles through alternate differential sedimentation and flotation, respectively in water and $40 \%$ sucrose solution, ending with a watery suspension (Reinecke 1973). For final 'cleaning' of the ova, the suspension of ova and faecal particles is poured into a flat-bottomed glass crystallising dish to a depth of about $3 \mathrm{~cm}$ and left to stand for about a minute before the contents of the dish are carefully poured at a slow and even pace into a second dish of the same sort. The ova, having a higher relative density than most of the faecal particles, sink relatively rapidly to the bottom and many of them adhere to the dish, whilst the majority of the faecal particles remain in the suspension that is poured off. The ova are harvested by washing into a beaker, with the use of a wash bottle. The process is repeated until few ova, appearing to the naked eye as a whitish, granular layer on the bottom of the dish, are visible after decantation.

The cleansed Nematodirus spp. ova are next cultured in water containing a pinch of potassium dichromate $\left(\mathrm{K}_{2} \mathrm{Cr}_{2} \mathrm{O}_{7}\right)$ to control fungal growth until the $\mathrm{L}_{3}$ have emerged. Continual aeration of the suspension seems to be beneficial for stimulating hatching. For Nematodirus spathiger, the yield of $\mathrm{L}_{3}$ can be improved considerably by storing the ova at about $4{ }^{\circ} \mathrm{C}$ for a week before incubation (Viljoen 1972). In the case of Nematodirus battus, formalin is added weekly to the culture over the 5-6 weeks of incubation to a final concentration of $1 \%$, incubating the ova for an hour and then washing them on a $53 \mu \mathrm{m}$ sieve before continued incubation (F. Jackson pers. comm., 1998 - Anonymous, 'Moredun Research Institute Parasitology Division standard operating procedures'). 
Nematodirus spp. ova can also be 'hatched' artificially (F. Jackson pers. comm., 1998 - Moredun SOPs): well cleansed, fully embryonated ova (i.e. on the point of hatching) are concentrated to obtain about $1 \mathrm{~mL}$ of solid material (eggs) per $10 \mathrm{~mL}$ of water. About $0.25 \mathrm{~mL}$ of egg suspension is pipetted in a line on a thick glass base plate measuring $300 \mathrm{~mm} \times 200 \mathrm{~mm} \times 8 \mathrm{~mm}$, covered with a similar 'crushing' glass plate and firm pressure is applied on the top plate until the ova are felt to crack. Stereoscopic examination should reveal that almost all the eggs have cracked, with larvae emerging. The larvae emerge fully when the preparation is re-suspended in water.

\section{Larva preservation}

Most $\mathrm{L}_{3}$ that die from natural causes or are killed (e.g. with heat) become granular and less translucent in appearance and tend to curl up, such as when killed with formalin. However, if alive, they can be relaxed and preserved practically unchanged in appearance for training and reference purposes. Formalin is added to a final concentration of about $1 \%-2 \%$ to the suspension of larvae, which are then killed by heating the suspension to $55^{\circ} \mathrm{C}-57^{\circ} \mathrm{C}$ for about a minute (note that most of the common infective larvae can survive for even some hours in much higher concentrations of formalin than the amount described above). Larvae killed and preserved in this way do not curl up, largely retain their brightly translucent appearance and their internal structures are more clearly discernable than those of $\mathrm{L}_{3}$ killed by heating alone (Van Wyk et al. 2004).

\section{Larva preparation for identification}

A drop of larval suspension is deposited on a glass microscope slide and the larvae killed with Lugol's iodine solution that is pre-diluted to a level where it takes a few minutes before the $\mathrm{L}_{3}$ become darkly stained. The reason for this is that it is more difficult to observe internal structures of larvae (such as the shape of the oesophagus that is important in some cases) and also to differentiate free-living nematodes from $\mathrm{L}_{3}$ of Bunostomum and Gaigeria spp. (which rapidly stain almost uniformly brown over their entire length) from the majority of the others, in which the cranial part of the larva initially stains considerably less intensively than the rest.

\section{Larva identification}

Note that, in this article, the tip of the cranial extremity of a larva is referred to as its 'head' and the caudal tip as its 'tail' (Figure 1) and the free sheath beyond the tail tip as the STE.

Morphological identification of $\mathrm{L}_{3}$ of most parasitic nematodes is based principally on examination of the caudal and cranial extremities, although other features such as the length or shape of the oesophagus or cranial refractile spots are important in some genera. Note, however, that once exsheathed, $\mathrm{L}_{3}$ of relatively few genera can be differentiated. Even when a space has formed between the cranial tip and the sheath of an aging larva, the characteristic shape of the head appears distorted and more squared than usual, thus increasing the chances of incorrect identification.

\section{Length of sheath tail extension}

The length of the STE is a very important criterion for identification and, to facilitate its application in larval differentiation, the STE of every larva being evaluated is related to that of Tr. colubriformis and Tr. axei. To this end, the length of the STE (' $c$ ' in Figure 1) of Tr. colubriformis and $\operatorname{Tr}$. axei $( \pm 33 \mu \mathrm{m})$ is represented by ' $\mathrm{X}$ ', to which that of each $\mathrm{L}_{3}$ encountered in a culture is related as follows:

Length of STE of $\mathrm{L}_{3}$ being identified ('c' in Figure 1) = STE / ' $\mathrm{X}$ '.

\section{Proportion of sheath tail extension comprising a filament}

If the STE ends in a narrow, thin filament (' $d$ ' in Figure 1), the proportion of the total length of the STE that this comprises is calculated, although with practice it can usually be estimated without the need for measurement. Note, however, that there is no exactly definable point of transition from the sheath filament to the cranial portion of the STE per genus or species; it is invariably a more or less gradual process, with no precise point of inflexion. On the other hand, because of relatively large differences in filament proportion between those species or genera such as Chabertia ovina and Oesophagostomum spp. that are difficult to differentiate (Table 1), this fact does not detract from its usefulness as a criterion for identification.

Individual values in Tables 1 and 2 were derived as described by Van Wyk et al. (2004). In some cases, the lengths of the STEs were not listed in the papers reviewed by them, but could be calculated from the tables, estimated from photographs and/or figures drawn to scale, or could be calculated from histograms (Keith 1953).

\section{Differential larval count}

\section{Identification procedure}

Firstly, a stage micrometer is used to determine, for each microscope objective lens, the number of divisions of the graticule in the ocular lens that span $33 \mu \mathrm{m}$; that is, the mean length of the STEs of Tr. axei and Tr. colubriformis, defined as ' $X$ ' for the purposes of the present system of identification (Table 1). Then the STEs of the $\mathrm{L}_{3}$ encountered in the diagnostic samples are compared, in turn, to the number of divisions (usually four divisions at $100 \times$ magnification) recorded for Tr. colubriformis and Tr. axei. Whilst the experienced person will use $10 \times$ ocular and objective microscope lenses (i.e. about $100 \times$ total magnification) or even somewhat less for the largest part of each differential count, about double this magnification will be necessary for the exceptional larval specimens that are difficult to identify, as well as for routine differentiation by the novice.

Conventionally, the first 100-200 $\mathrm{L}_{3}$ encountered per count are identified for estimating the proportion of a given sample which each genus comprises. Whilst $\mathrm{L}_{3}$ can generally be identified only to genus, this is not absolute. Because the $\mathrm{L}_{3}$ of Trichostrongylus spp. of small ruminants are difficult to differentiate from those of Teladorsagia spp., they are commonly grouped during the count. However, 
TABLE 1: Measurements of third-stage larvae of small ruminants, including sheath tail extension ${ }^{a},{ }^{\prime} X^{\prime}$-values and the proportion of the sheath tail extension comprising a filament.

\begin{tabular}{|c|c|c|c|c|c|}
\hline \multirow[t]{2}{*}{ Nematode } & \multicolumn{2}{|c|}{ Length of STE $(\mu \mathrm{m})$} & \multicolumn{2}{|c|}{ ' $X$ '-value of STE } & \multirow[t]{2}{*}{ Filament (\% of STE) ${ }^{\mathrm{b}}$} \\
\hline & Mean & Range & Mean & Range & \\
\hline Trichostrongylus spp. ${ }^{\mathrm{c}}$ & 30 & $18-32$ & 1.0 & $0.6-1.1$ & $\mathrm{Nil}$ \\
\hline $\begin{array}{l}\text { Trichostrongylus falculatus and } \\
\text { Trichostrongylus rugatus }\end{array}$ & 51 & $46-56$ & 1.7 & - & $\mathrm{Nil}$ \\
\hline Haemonchus contortus & 74 & $65-82$ & 2.5 & $2.2-2.7$ & $10-15$ \\
\hline Teladorsagia circumcincta & 35 & $30-44$ & 1.2 & $1.0-1.5$ & $\mathrm{Nil}$ \\
\hline Cooperia spp. (mainly Cooperia curticei) & 46 & $39-52$ & 1.5 & $1.3-1.7$ & $20-25$ \\
\hline Cooperia spp. (from antelope) ${ }^{d}$ & 58 & - & 1.9 & - & - \\
\hline Oesophagostomum venulosum & 168 & 122-207 & 5.6 & $4.1-6.9$ & - \\
\hline Oesophagostomum columbianum & 153 & $125-188$ & 5.1 & $4.2-6.3$ & $60-70$ \\
\hline Chabertia ovina & 123 & $101-150$ & 4.1 & $3.4-5.0$ & 25 \\
\hline Bunostomum trigonocephalum & 99 & $85-115$ & 3.3 & $2.8-3.8$ & $40-50$ \\
\hline Gaigeria pachyscelis & 132 & $128-135$ & 4.4 & $4.3-4.5$ & 50 \\
\hline Nematodirus filicollis & 261 & - & 8.7 & - & 50 \\
\hline Nematodirus battus & 171 & - & 5.7 & - & - \\
\hline
\end{tabular}

STE, sheath tail extension.

a, For sources from which the values in the table were obtained, see Van Wyk, J.A., Cabaret, J. \& Michael, L.M., 2004, 'Morphological identification of nematodes of small ruminants and cattle simplified', Veterinary Parasitology 119, 277-306. http://dx.doi.org/10.1016/j.vetpar.2003.11.012, PMid:15154594

, For calculation of mean ' $X$ '-values, the mean of Trichostrongylus spp. of sheep was used (Van Wyk et al. 2004 - see above).

c, Proportion of the STE that is filamentous (J. Van Wyk pers. obs., 1990, unless otherwise indicated in text).

¿, Cooperia fuelleborni, Paracooperia serrata, Cooperioides antidorca (Mönnig, 1931).

TABLE 2: Measurements of third-stage larvae of cattle, including sheath tail extensiona, ' $X$ '-values and the proportion of the sheath tail extension comprising a filament. Nematode $\quad$ Length of STE ( $\mu \mathrm{m}) \quad$ ' $X^{\prime}$-value of STE ${ }^{\mathrm{b}}$

\begin{tabular}{|c|c|c|c|c|c|}
\hline \multirow[t]{2}{*}{ Nematode } & \multicolumn{2}{|c|}{ Length of STE $(\mu \mathrm{m})$} & \multicolumn{2}{|c|}{ ' $X$ '-value of STE ${ }^{b}$} & \multirow[t]{2}{*}{ Filament $\left(\%\right.$ of STE) ${ }^{c}$} \\
\hline & Mean & Range & Mean & Range & \\
\hline Trichostrongylus axei & 32 & $25-41$ & 1.1 & $0.8-1.4$ & 0 \\
\hline Haemonchus placei & 102 & $80-119$ & 3.4 & $2.7-4.0$ & 20 \\
\hline Cooperia pectinata / punctata & 59 & $37-78$ & 2.0 & $1.2-2.6$ & 20 \\
\hline Cooperia oncophora & 94 & $65-116$ & 3.1 & $2.2-3.9$ & 20 \\
\hline Bunostomum phlebotomum & 73 & $58-96$ & 2.4 & $1.9-3.2$ & 50 \\
\hline Nematodirus helvetianus & 250 & $203-283$ & 8.3 & $6.8-9.4$ & 50 \\
\hline Nematodirus battus & 165 & - & 5.2 & - & - \\
\hline
\end{tabular}

STE, sheath tail extension.

a, For sources from which the values in the table were obtained, see Van Wyk, J.A., Cabaret, J. \& Michael, L.M., 2004, 'Morphological identification of nematodes of small ruminants and cattle simplified', Veterinary Parasitology 119, 277-306. http://dx.doi.org/10.1016/j.vetpar.2003.11.012, PMid:15154594

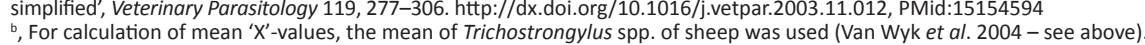

c, Proportion of the STE that is filamentous (J. Van Wyk pers. obs., 1990, unless otherwise indicated in text).

when exsheathed, $\mathrm{L}_{3}$ of Nematodirus spp. and intestinal Trichostrongylus spp. can be differentiated from those of Tr. axei and Teladorsagia spp. in having digitate appendages on the tail, whilst the others have none (Figure 2 [McMurtry et al. 2000] and Figure 3).

Whilst exsheathing of intestinal Trichostrongylus spp. aids in their identification, larvae that are exsheathed are often difficult to differentiate, as mentioned above. This impasse of having to differentiate some $\mathrm{L}_{3}$ after they have been exsheathed whilst others must perforce be ensheathed can be overcome to some extent by conducting differential counts in two steps. Initially, ensheathed Trichostrongylus, Teladorsagia species are grouped, whilst the rest are identified to the level of genus or species. Thereafter, as a second step, the $\mathrm{L}_{3}$ are exsheathed and only those with specific digitate terminal caudal appendages (Figure 2, intestinal Trichostrongylus spp.) are differentiated from the rest of the first 100-200 encountered. Subsequently, the proportion of Teladorsagia spp. can be computed as follows:
- Step 1: Do differential count of ensheathed $\mathrm{L}_{3}$ and let $\%$ Teladorsagia spp. + Trichostrongylus spp. $=x$.

- Step 2: Exsheathe the $\mathrm{L}_{3}$ and repeat differential count. Let $\%$ intestinal Trichostrongylus spp. (McMurtry et al. 2000) $=y$. Then \% Teladorsagia spp. + Tr. axei $=x-y$.

Unfortunately, with the above approach it is not possible to differentiate Tr. axei from Teladorsagia spp., but if it is important to do so, the method of Lancaster and Hong (1987) can be employed as follows during the first step for a rough estimate, whilst keeping in mind that Cabaret (pers. comm., 2003) experienced the Lancaster and Hong (1987) technique to have a wide margin of error (see discussion below):

- Step 1: Do differential count of ensheathed $\mathrm{L}_{3}$ and let $\%$ Teladorsagia spp. (Lancaster \& Hong 1987) $=x$; and let \% Trichostrongylus spp. (Lancaster \& Hong 1987) $=y$.

- Step 2: Repeat differential count after having exsheathed the $\mathrm{L}_{3}$ and let \% intestinal Trichostrongylus spp. (McMurtry et al. 2000) $=z$. Then \% T. axei $=y-z$. 


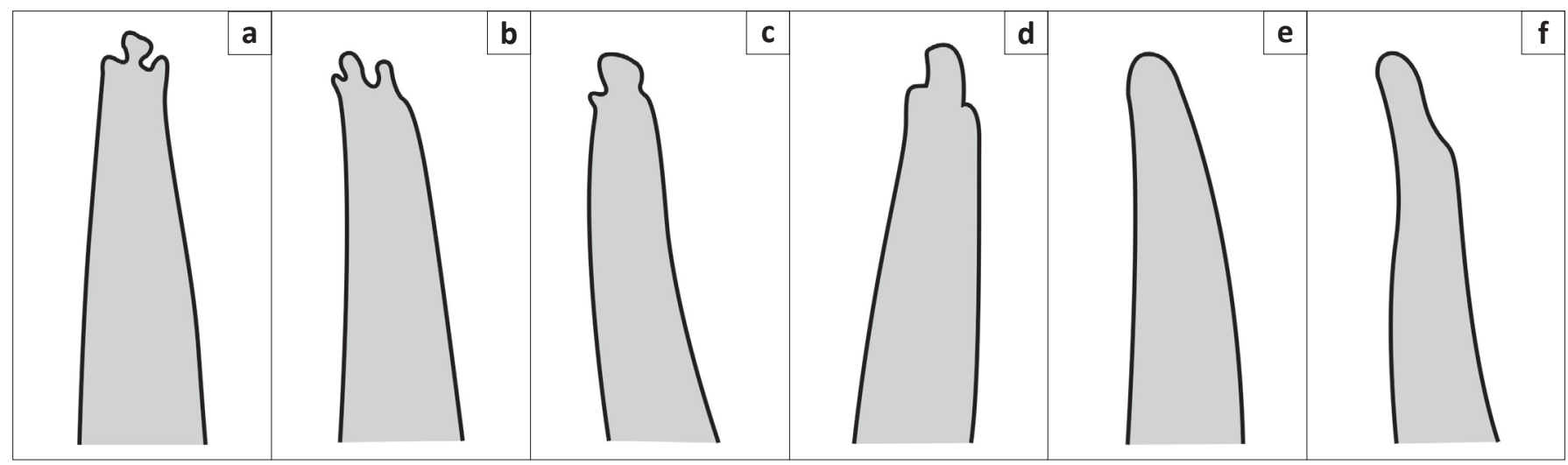

Source: Drawn from McMurtry, L.W., Donaghy, M.J., Vlassoff, A. \& Douch, P.G.C., 2000, 'Distinguishing morphological features of the third larval stage of ovine Trichostrongylus spp.', Veterinary Parasitology 90, 73-81. http://dx.doi.org/10.1016/S0304-4017(00)00230-2

FIGURE 2: Identification to species level of Trichostrongylus spp., based on differences in the morphology of the tips of the larva tails: (a, b) Trichostrongylus colubriformis, (c, d) Trichostrongylus vitrinus, (e) Trichostrongylus axei and (f) Teladorsagia circumcincta.

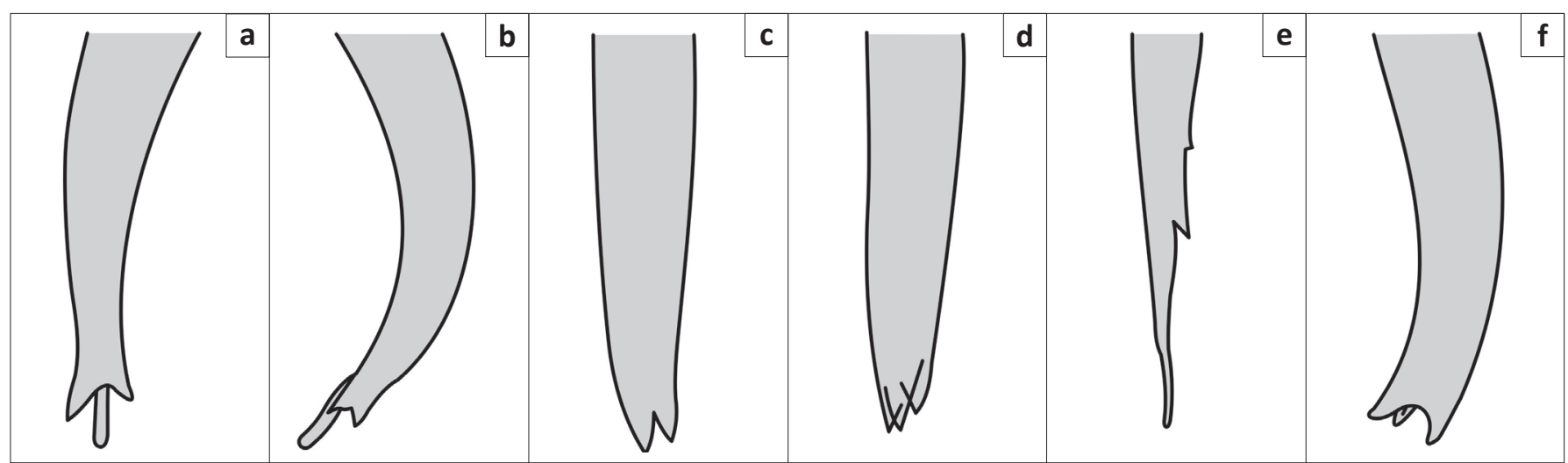

Source: Drawn from Van Wyk, J.A., Cabaret, J. \& Michael, L.M., 2004, 'Morphological identification of nematodes of small ruminants and cattle simplified', Veterinary Parasitology 119, 277-306. http:// dx.doi.org/10.1016/j.vetpar.2003.11.012, PMid:15154594

FIGURE 3: Terminal appendages of Nematodirus spp. exsheathed third-stage larvae: (a) Nematodirus spathiger, lateral view, (b) Nematodirus spathiger, dorso-lateral view, (c) Nematodirus filicollis, lateral view, (d) Nematodirus filicollis, ventro-lateral view, (e) Nematodirus battus, lateral view and (f) Nematodirus abnormalis, lateral view.

\section{Ethical considerations}

This article is based on research conducted in the 1970s and early 1980s. Whilst it was carried out strictly in accordance with ethical considerations overseen by the management of the Onderstepoort Veterinary Research Institute, at that stage there were no national or international guidelines for work of this nature of which the authors were aware. In 2004, a novel method of larvae evaluation was identified and described from the work of Van Wyk et al. (2004) and the present study illustrates this in terms of the differences between the larvae, whilst, at the same time, accurately drawing the STE filaments (this having been developed only recently, but without the need for further research in animals).

\section{Results and discussion Differentiation of larvae}

Most importantly, as emphasised by Mönnig (1931), is the selection of only those points of comparison between $\mathrm{L}_{3}$ of the various genera and species that will enable swift identification with the minimum number of measurements. It is also necessary to acquaint yourself with the variation in the appearance of the various features under different depths of focus of the microscope.
It is exceedingly difficult to photograph larval STEs such that both the tip of the STE and the rest of the caudal extremity of a given larva is in focus simultaneously. Hence the excellent photographs in the papers of Corticelli and Lai (1964) and Henriksen (1972), and to some extent also of Keith (1953), deserve particular mention, as these workers succeeded particularly well, and their photos can be put to very good use when training inexperienced persons to identify $\mathrm{L}_{3}$. On the other hand, some of the modern electronic photomicroscopes are able to integrate a series of photos at different depths of focus into a composite picture with the entire sheath tail in focus and this could be used fruitfully to this end.

Tables 1 and 2 contain summaries of the mean measurements and corresponding ' $X$ '-values of the different common worm genera and/or species (see Van Wyk et al. 2004, Tables $1-7$, for details gleaned from the literature). $L_{3}$ of parasitic nematode genera are illustrated in this article in Figures 2-13.

As discussed by Van Wyk et al. (2004), in most cases where drawings were published previously, the shapes of the heads (cranial extremities) of the larvae and the proportional lengths of the filamentous portions of the STEs were not drawn accurately to scale. Many of the differences between worm genera are very small, making it difficult to observe 


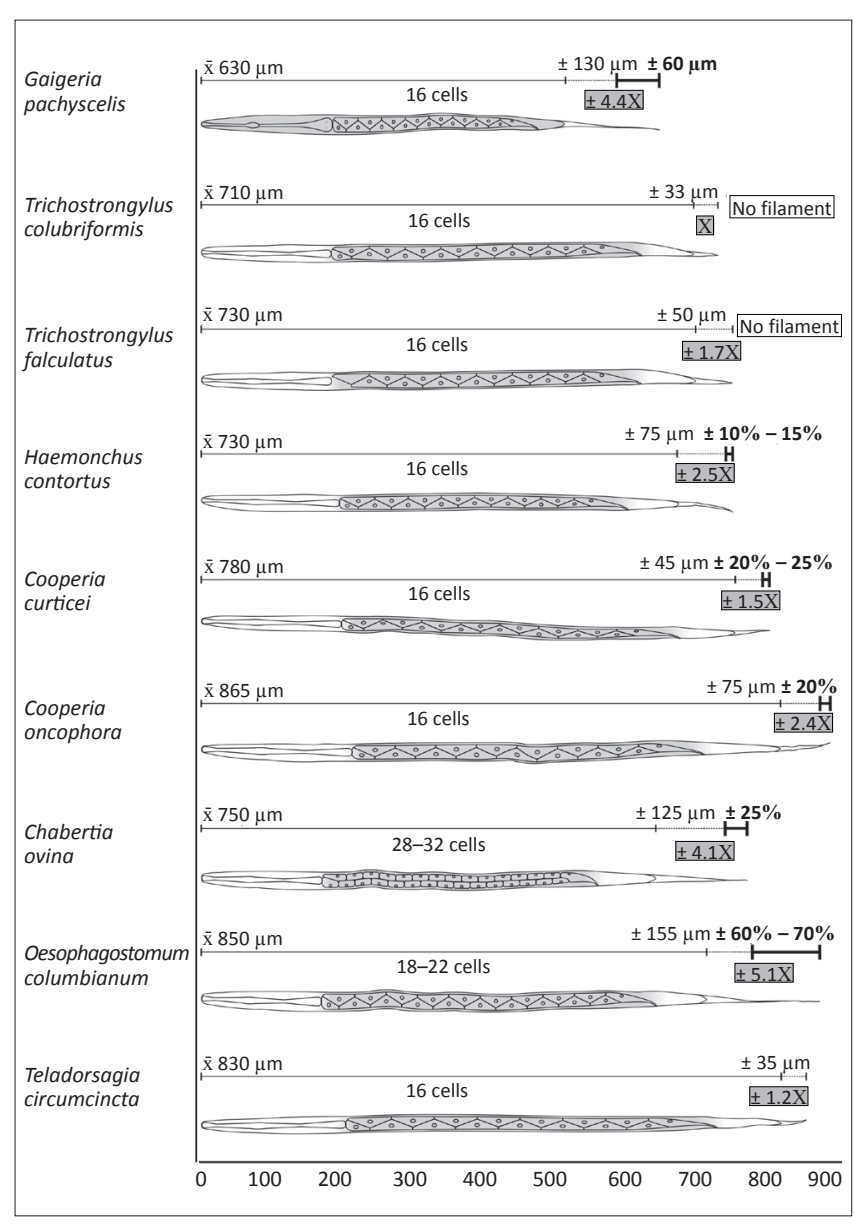

FIGURE 4: Third-stage larvae of common nematodes of small ruminants, measured in micrometres $(\mu \mathrm{m})$. and even more difficult to draw accurately. There are notable exceptions, such as the drawings of Borgsteede and Hendriks (1974), which are relatively accurate regarding the morphology of both the heads and STEs of the $\mathrm{L}_{3}$; yet, identification remained so difficult, especially for the inexperienced, that another morphological feature was sought that could simplify the process. The sheath tail filament presented this possibility.

The potential of the STE filament for differentiation of $\mathrm{L}_{3}$ was not recognised previously. Most earlier workers either did not take it into consideration as a distinguishing feature, or it was mentioned in general without investigating its potential for identifying $\mathrm{L}_{3}$ to the level of genus or species (Corticelli \& Lai 1964; Gibbons et al. 2012). This omission could perhaps be ascribed to the fact that, as mentioned, the transition between the filament and the rest of the STE is not sharp and thus cannot be pinpointed with certainty, especially because it is also affected by the depth of focus of the microscope.

With few exceptions, such as some Nematodirus spp. and intestinal Trichostrongylus spp., the infective larvae of the common nematodes of domestic ruminants can be identified only to genus level. However, as differences between species of a given genus in characteristics such as pathogenicity and, to some extent, susceptibility to anthelmintics are generally small, this limitation is seldom a serious disadvantage.

Morphological differences between some genera (e.g. Trichostrongylus spp. and Teladorsagia spp.) are so small that

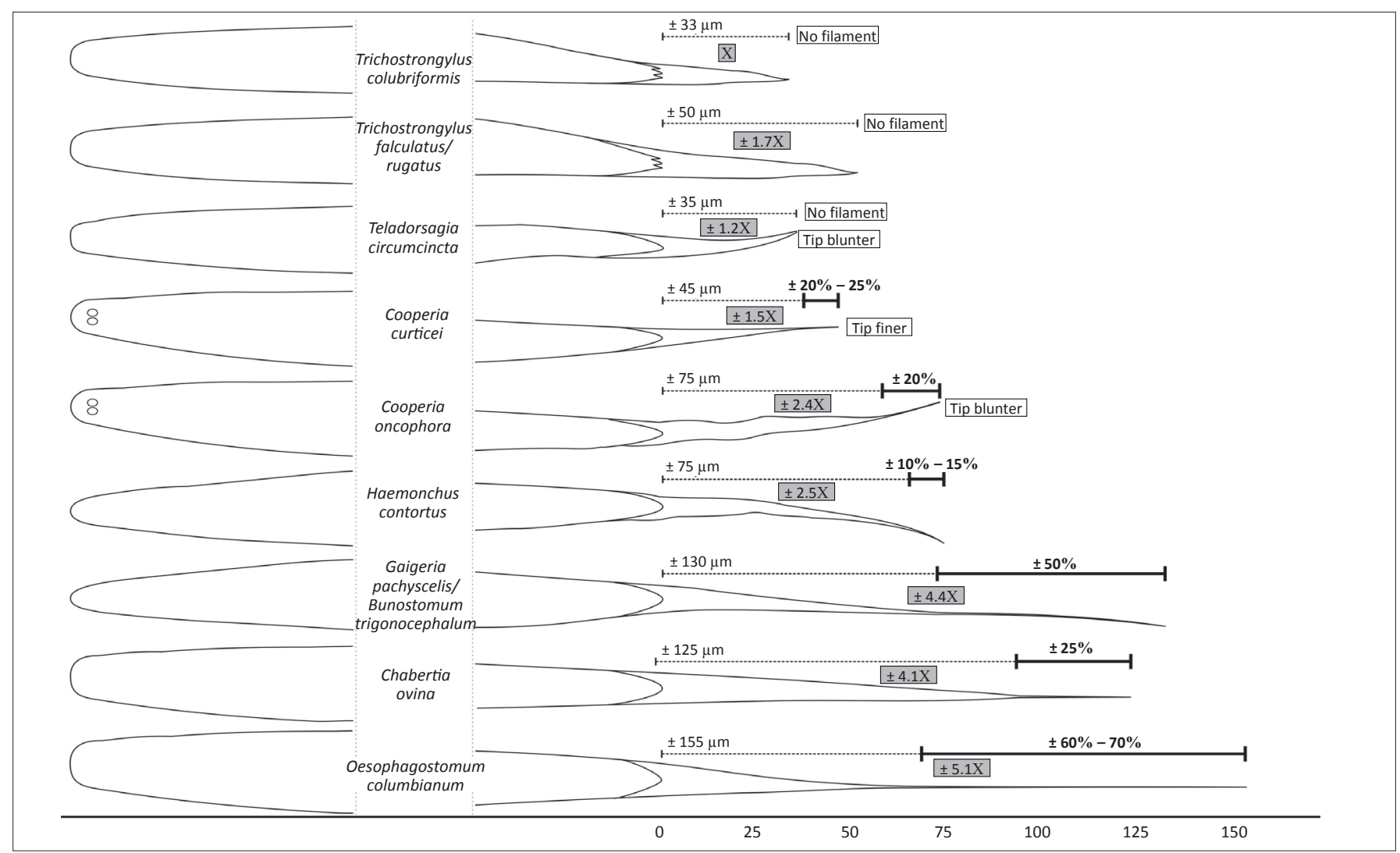

FIGURE 5: Cranial and caudal extremities of third-stage larvae of common nematodes of small ruminants, measured in micrometres ( $\mu \mathrm{m})$. 


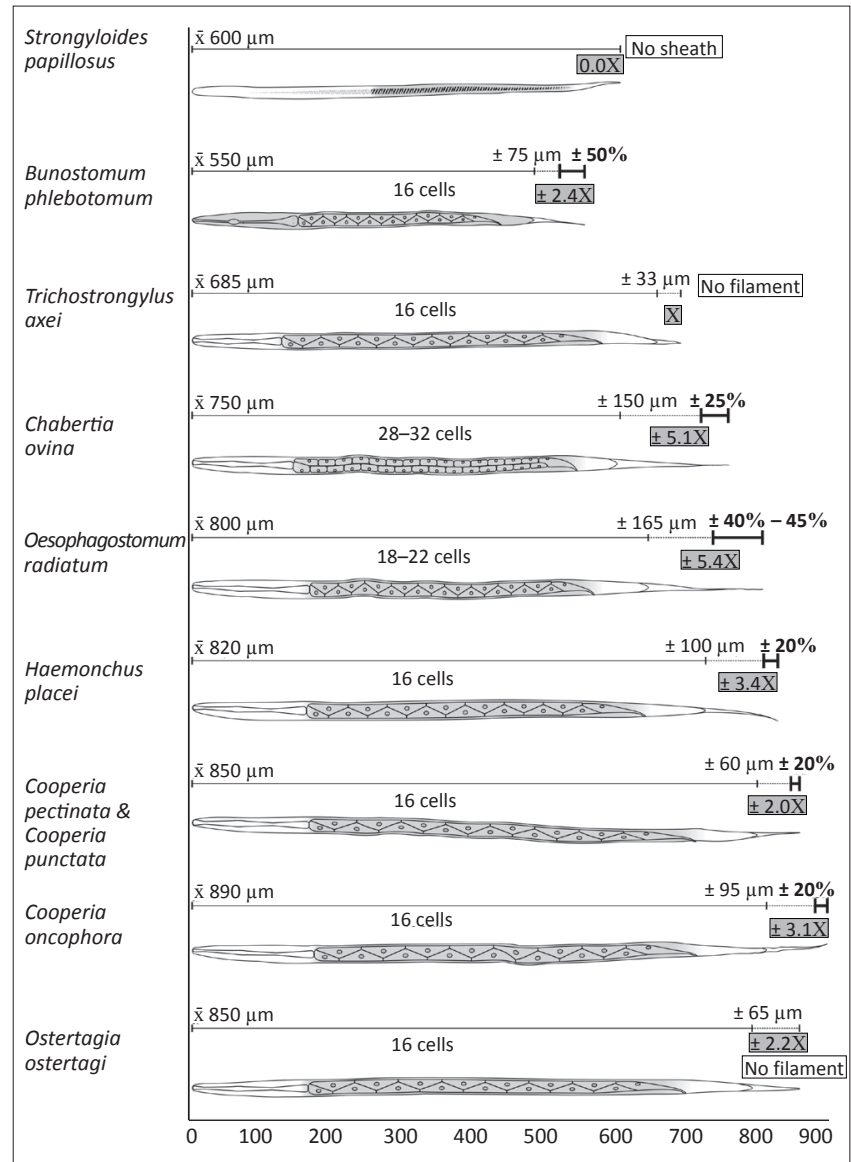

FIGURE 6: Third-stage larvae of common nematodes of cattle, measured in micrometres $(\mu \mathrm{m})$. the ' $\mathrm{X}$ ' system is ineffective for differentiation and the STEs have no filaments. However, these are the exceptions, as the differences are mostly large enough to make it possible after a few measurements (in divisions on the graticule) of $\mathrm{L}_{3}$ in a mixed culture to judge the various ' $X$ '-values without the necessity for many (if any) further measurements. Experience has shown that even relatively small differences can be recognised without recourse to measurement. For instance, whilst this system was in the early stages of development we became alerted, without having to resort to measurements, to a pure culture of Trichostrongylus falculatus (the sheath tail of which differs from the common Trichostrongylus spp. by only $0.5^{\prime} X^{\prime}$ ) when faecal samples were submitted after a field outbreak of deaths in sheep in the Free State Province. On the other hand, variations within species or genera (Tables 1 and 2) must be kept in mind and it remains essential to take note of and to use other morphological features, such as the shape of the head (Figures 5-8, 14 and 15) and the refractile bodies in the heads of Cooperia spp. (below), in addition to the ' $X$ ' system. It is also advisable to have $\mathrm{L}_{3}$ of at least Tr. colubriformis and/or Tr. axei, but preferably of more genera, in pure culture available in each laboratory where either diagnostic or research differential larval counting is performed. Only small numbers of these $\mathrm{L}_{3}$ are required at a time, with the result that a single batch killed and preserved as described above can suffice for years.

Figures 14 and 15 are organograms that can function as illustrated, interactive keys for the stepwise morphological

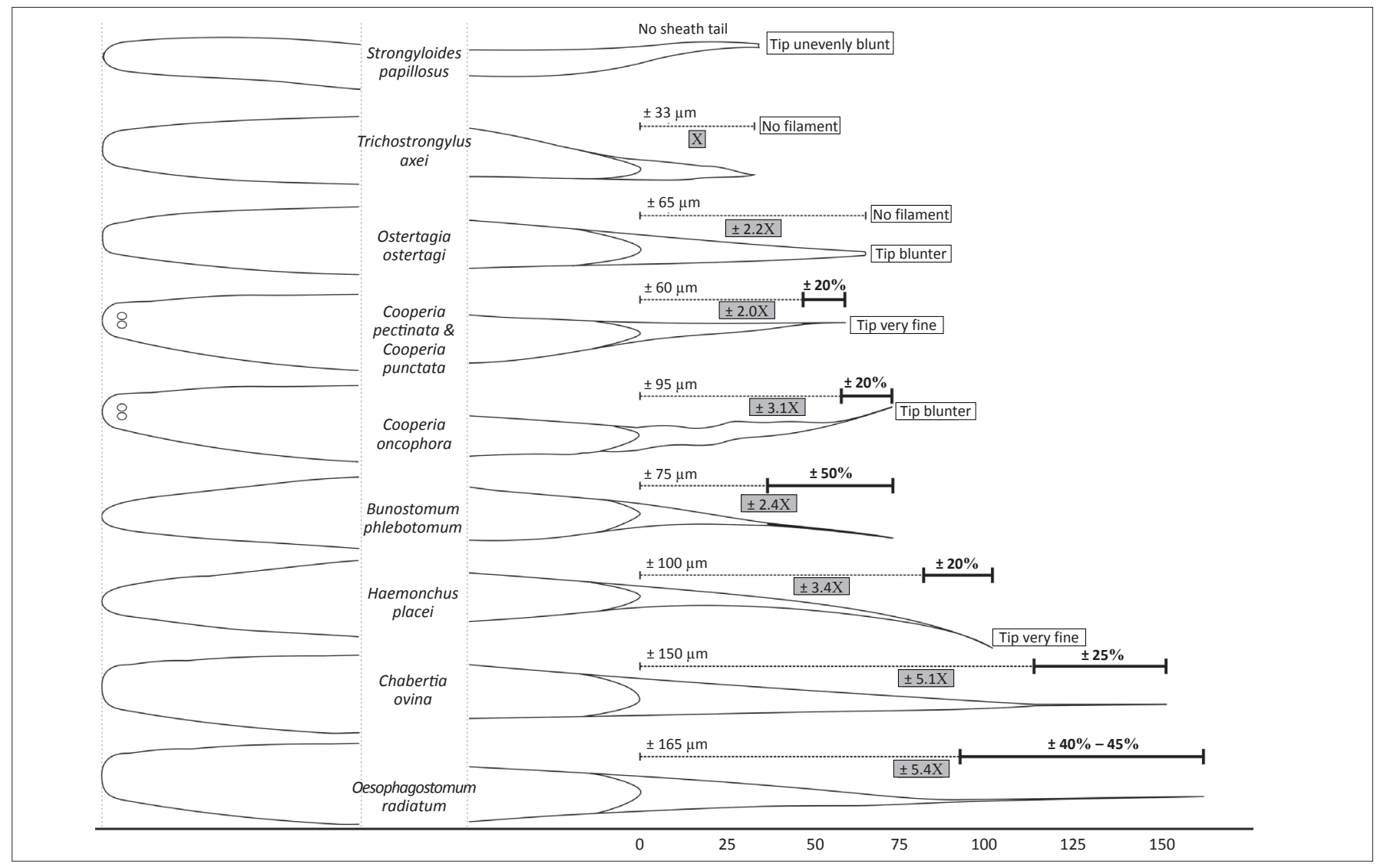

FIGURE 7: Cranial and caudal extremities of third-stage larvae of common nematodes of cattle, measured in micrometres ( $\mu \mathrm{m})$. 


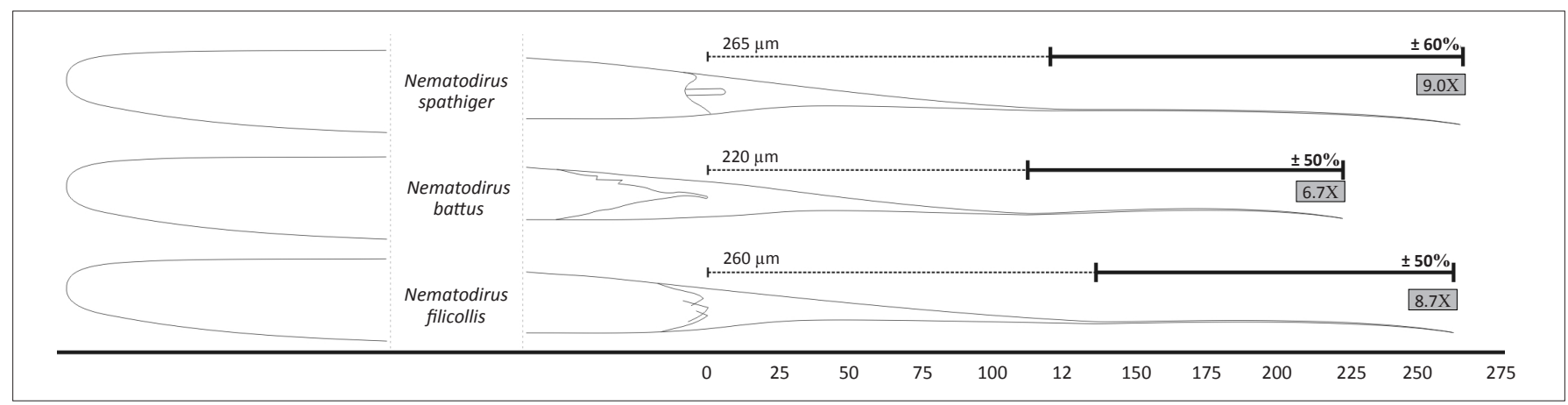

FIGURE 8: Cranial and caudal extremities of ensheathed third-stage larvae of Nematodirus spp., measured in micrometres ( $\mu \mathrm{m}$ ).

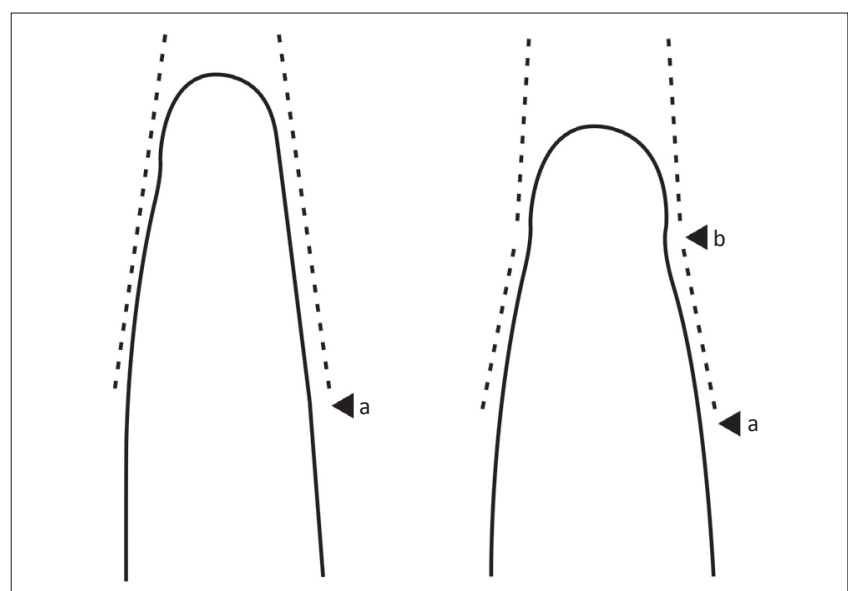

Source: Drawn from Lancaster, M.B. \& Hong, C., 1987, 'Differentiation of third stage larvae of "ovine Ostertagia" type and Trichostrongylus species', The Veterinary Record 120, 503. http://dx.doi.org/10.1136/vr.120.21.503, PMid:3604011

FIGURE 9: Differentiation of third-stage larvae of Trichostrongylus spp. (left) and Ostertagia spp. (right), depicting (a) initial point of inflexion craniad and (b) 'shoulder' of Ostertagia spp.

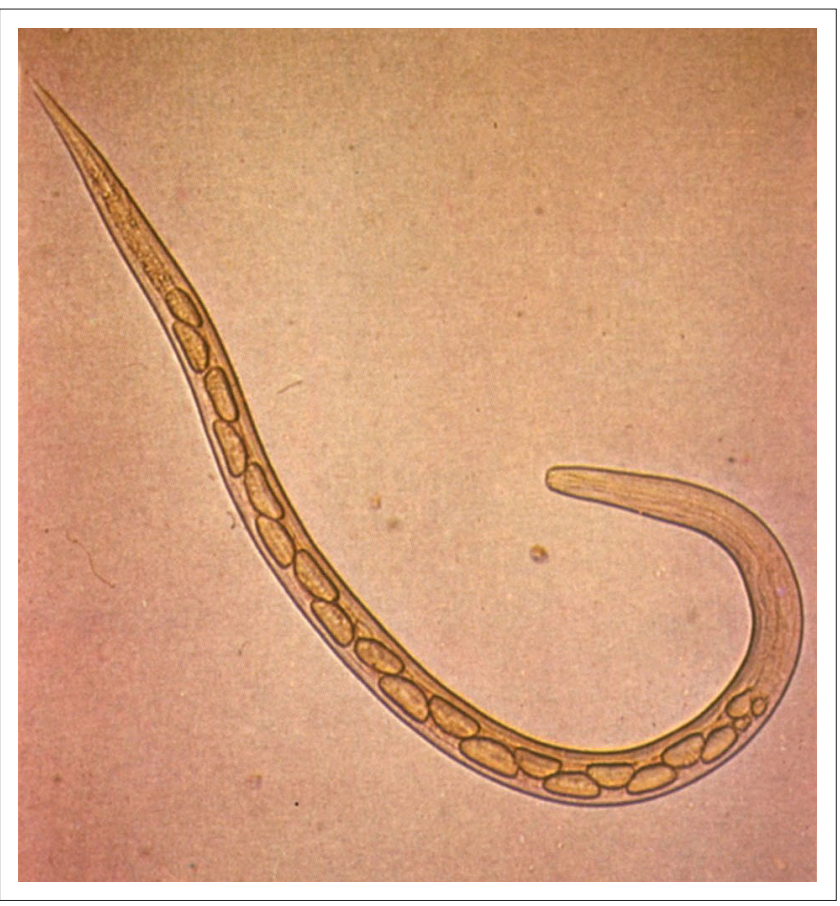

Source: Reproduced from Van Wyk, J.A., 1977, 'A rapid method for differentiating between the infective larvae of Oesophagostomum columbianum and Chabertia ovina', Onderstepoort Journal of Veterinary Research 44, 197-199. PMid:614536

FIGURE 10: Exsheathed third-stage larva of Oesophagostomum columbianum with a total of 20 or 21 intestinal cells (larva thawed after having been frozen in liquid nitrogen). identification of common nematode $\mathrm{L}_{3}$ of small ruminants and cattle, respectively. They were compiled largely for the purpose of training of the inexperienced and are intended for use together with the various figures depicting prominent distinguishing features of the morphology of the $\mathrm{L}_{3}$ concerned.

\section{Salient features of $\mathrm{L}_{3}$ of the common nematode genera and/or species}

\section{Trichostrongylus spp.}

Whilst very similar, there are some distinguishing features between different Trichostrongylus species of domestic ruminants, for instance in length of STE (e.g. ' $X$ ' and no filament in $T r$. colubriformis and Tr. axei and 1.7 ' $\mathrm{X}$ ' in Tr. falculatus and Trichostrongylus rugatus) (O'Callaghan 2004; Van Wyk et al. 2004) and the presence or absence of digitate appendages on the caudal extremity of the larvae (Figure 2) (McMurtry et al. 2000). Common to all the Trichostrongylus species included in this article is that the STE is without a filament and tapers so sharply that it resembles the point of a sharpened wooden pencil. The very short STE of Tr. colubriformis and Tr. axei is used as the basis of the classification system (Van Wyk et al. 2004). When exsheathed, the $\mathrm{L}_{3}$ of $T r$. axei resemble those of Teladorsagia spp. in that the tip of the tail is smooth, in contrast to the irregular protuberances mentioned for intestinal Trichostrongylus spp. However, the differences can be discerned only at high magnification and are usually visible only in larvae that are exsheathed. Hence, as mentioned above, this feature requires a second step in the differential larval count procedure.

\section{Ostertagia and Teladorsagia spp.}

Small ruminants: The STE of the Teladorsagia spp. of small ruminants overlaps considerably in length with that of Trichostrongylus spp. and is very similar in appearance, resembling a sharpened pencil point, and both are without a terminal filament (Table 1). Added to this is that, as mentioned, the tip of the tail of the Teladorsagia spp. $\mathrm{L}_{3}$ is smooth, similar to that of Tr. axei. According to Lancaster and Hong (1987), the head of ovine Teladorsagia species has a slight 'shoulder' close to its cranial tip (illustrated in Figure 9), whilst that of Trichostrongylus spp. does not. This is fully described and depicted in Lancaster and Hong (1987) and Van Wyk et al. (2004). Note, however, that J. Cabaret 
(pers. comm., 2003) reported an average of 30\% incorrect identifications with use of this method for differentiating Tr. colubriformis and Teladorsagia circumcincta in mixed culture.

Whilst Tr. axei and Te. circumcincta do differ markedly in total length (with respective means of $720 \mu \mathrm{m}$ and $820 \mu \mathrm{m}$ ), it is

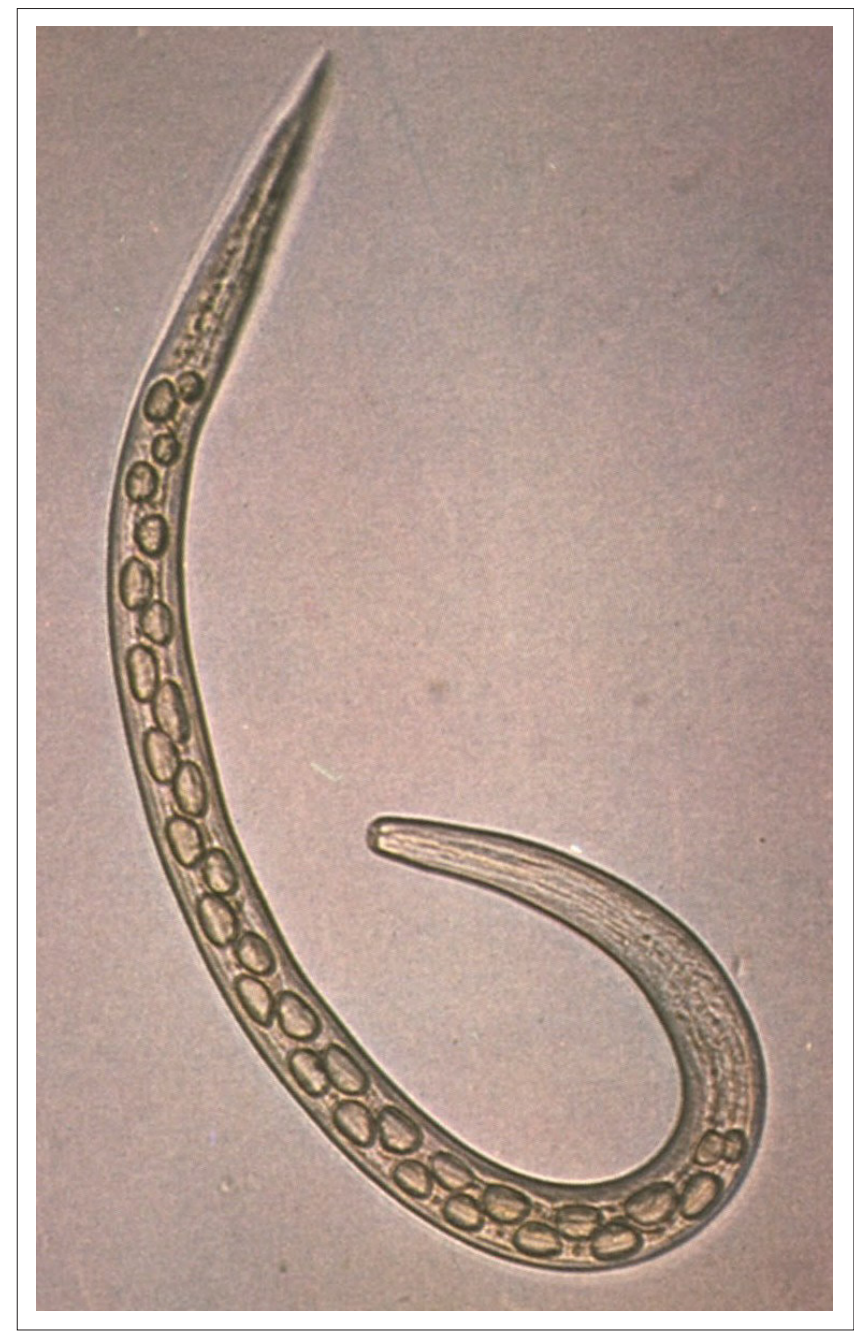

Source: Reproduced from Van Wyk, J.A., 1977, 'A rapid method for differentiating between the infective larvae of Oesophagostomum columbianum and Chabertia ovina', Onderstepoort Journal of Veterinary Research 44, 197-199. PMid:614536

FIGURE 11: Exsheathed third-stage larva of Chabertia ovina, with a total of 32 intestinal cells (larva thawed after having been frozen in liquid nitrogen). time-consuming to do such measurements. Furthermore, the lengths of the $\mathrm{L}_{3}$ of Trichostrongylus spp. and Teladorsagia spp. overlap to a considerable extent (O'Callaghan 2004), thus making it a relatively impractical for accurate discrimination.

Cattle: In this host species, in contrast to the situation in small ruminants, there is small chance of confusing the STEs of Ostertagia ostertagi and Trichostrongylus spp. $\mathrm{L}_{3}$. At slightly more than 2 ' $X$ ', the STE of $L_{3}$ of Os. ostertagi is twice as long as that of the common Trichostrongylus spp. and the presence of a short filament serves further to differentiate them from the $\mathrm{L}_{3}$ of both Te. circumcincta and Trichostrongylus spp. (Tables 1 and 2). Another useful distinguishing feature is that the STE of Os. ostertagi ends in a blunter tip than that of Haemonchus placei (Borgsteede \& Hendriks 1974) (Figures 6 and 7).

\section{Haemonchus spp.}

As discussed by Van Wyk et al. (2004), there has been confusion in the past concerning the validity of $H$. placei as a separate species from Haemonchus contortus, despite clear morphological and/or biological distinguishing features between the two both in the $\mathrm{L}_{3}$ and adult worms. The confusion was compounded by cross-infectivity of both species to sheep and cattle. The adults of the two species are indeed relatively difficult to differentiate morphologically, but with use of the novel approach to differentiation presented now, this should not apply to the $\mathrm{L}_{3}$.

Whilst the infective larva of $H$. contortus of small ruminants has an STE with a length of 2.2-2.7 ' $\mathrm{X}$ ' and a filament comprising $10 \%-15 \%$ thereof, the corresponding values of $H$. placei of cattle are 2.7-4.0 ' $\mathrm{X}^{\prime}$ and $\pm 20 \%$ (Figures $4-7$ and Tables 1 and 2). On the other hand, Borgsteede and Hendriks (1974) discuss the possibility of confusion between the $\mathrm{L}_{3}$ of H. placei and of Os. ostertagi in cattle and point out the respective bullet-shaped and flatter heads and much finer and blunter STE tips of Os. ostertagi and H. placei (see Figures 6 and 7 in this article, as well as subsection 3.1.3. of Van Wyk et al. 2004 and, particularly, Figure 3 of Borgsteede \& Hendriks 1974). Added to this is that the filament comprises a larger proportion of the STE of $H$. placei than it does in Os. ostertagi (Table 2) (Van Wyk et al. 2004) and, as discussed

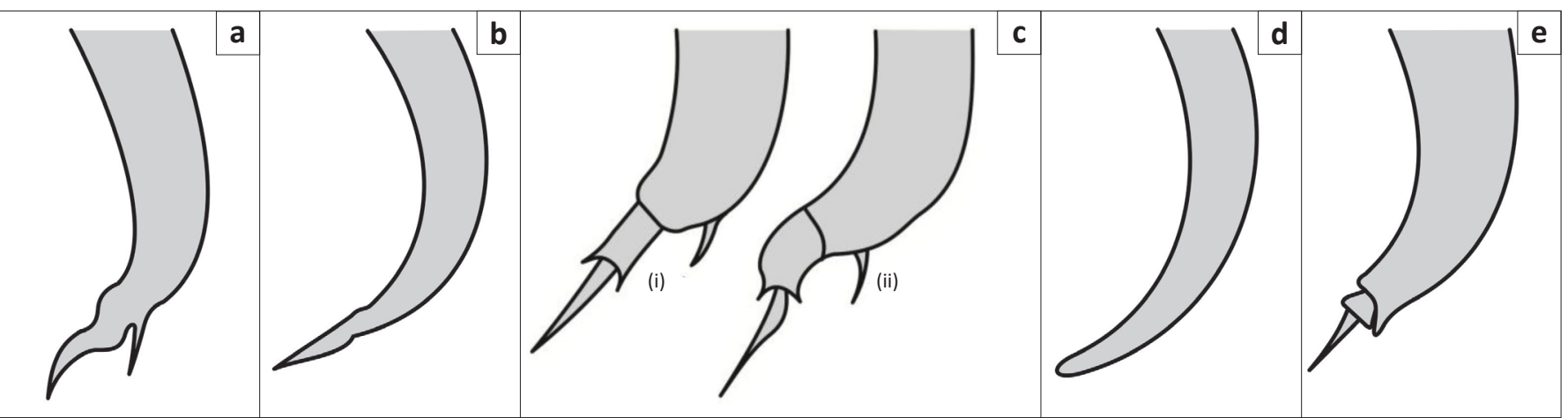

Source: Drawn from Van Wyk, J.A., Cabaret, J. \& Michael, L.M., 2004, 'Morphological identification of nematodes of small ruminants and cattle simplified', Veterinary Parasitology 119, 277-306. http:// dx.doi.org/10.1016/j.vetpar.2003.11.012, PMid:15154594

FIGURE 12: Tail morphology of lungworm larvae of five genera: (a) Muellerius capillaris, (b) Protostrongylus rufescens, (c) Cystocaulus ocreatus, (d) Dictyocaulus filaria and (e) Neostrongylus linearis, with (i) and (ii) illustrating the different types of appendices to the larva tails. 
by Van Wyk et al. (2004), the intestine of Haemonchus spp. is reported to end caudally in two terminal cells, compared to only one in Ostertagia spp.

\section{Cooperia spp.}

Most striking is the presence of two unique refractile bodies in the head of the $\mathrm{L}_{3}$ of Cooperia spp. (Figures 4-7), constituting an important distinguishing feature from those

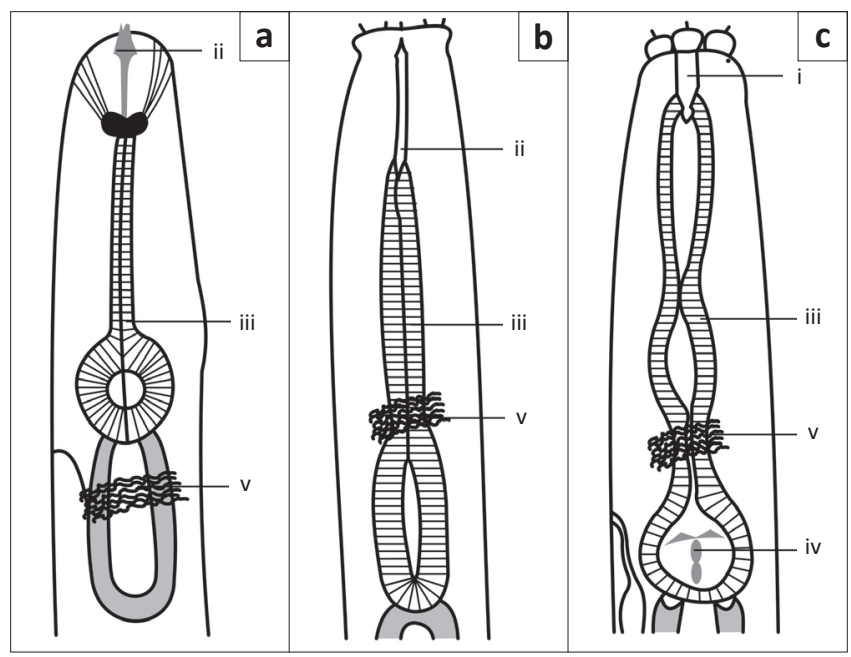

Source: Drawn from Van Wyk, J.A., Cabaret, J. \& Michael, L.M., 2004, 'Morphological identification of nematodes of small ruminants and cattle simplified', Veterinary Parasitology 119, 277-306. http://dx.doi.org/10.1016/j.vetpar.2003.11.012, PMid:15154594

FIGURE 13: Morphology of the cranial extremities (heads) of free-living nematodes: (a) Tylenchida, (b) Dorylaimida and (c) Rhabditida, depicting, (i) stoma, (ii) stylet, (iii) oesophagus, (iv) valve and (v) nerve ring. of other genera. On the other hand, the STEs of Cooperia pectinata and Cooperia punctata of cattle somewhat resemble those of Os. ostertagi and H. placei, all having a filament of about 20\% (Table 2). However, in addition to the refractile bodies of Cooperia spp., the head of the $\mathrm{L}_{3}$ of Os. ostertagi is considerably more squared than that of Cooperia spp. or $H$. placei. In contrast, the STE of Cooperia oncophora in cattle is \pm 3 ' $X^{\prime}$, more closely resembling the $L_{3}$ of $H$. placei than that of Os. ostertagi. Another distinguishing feature of C. oncophora is that the caudal tip of the sheath of $C$. oncophora is clearly perceptible, whereas that of $C$. punctata 'appears to vanish into nothingness' (Borgsteede \& Hendriks 1974), or is 'refractile in appearance' (Anonymous 1977). Borgsteede and Hendriks (1974) also describe the head of the $\mathrm{L}_{3}$ of C. oncophora to be somewhat broader than that of C. punctata, although we have found this difference to be difficult to visualise.

Notably, as reviewed by Van Wyk et al. (2004), the mean lengths of the STEs of $C$. oncophora $\mathrm{L}_{3}$ cultured from sheep differ significantly from those from cattle. The respective lengths are about $73 \mu \mathrm{m}\left(2.4^{\prime} X^{\prime}\right.$, Table 1) and $94 \mu \mathrm{m}\left(3.1^{\prime} X^{\prime}\right.$, Table 2), with corresponding ranges of $62 \mu \mathrm{m}-82 \mu \mathrm{m}$ and $65 \mu \mathrm{m}-116 \mu \mathrm{m}$, hence with little overlapping in the lengths of their STEs, as confirmed by the fact that Hansen and Shivnani (1956) recorded only one measurement of less than $79 \mu \mathrm{m}$ for C. oncophora from cattle and Dikmans and Andrews (1933) recorded a maximum of $82 \mu \mathrm{m}$ for this species from sheep.

The Cooperia curticei $\mathrm{L}_{3}$ of sheep has an STE more closely resembling that of $C$. pectinata and C. punctata than that of

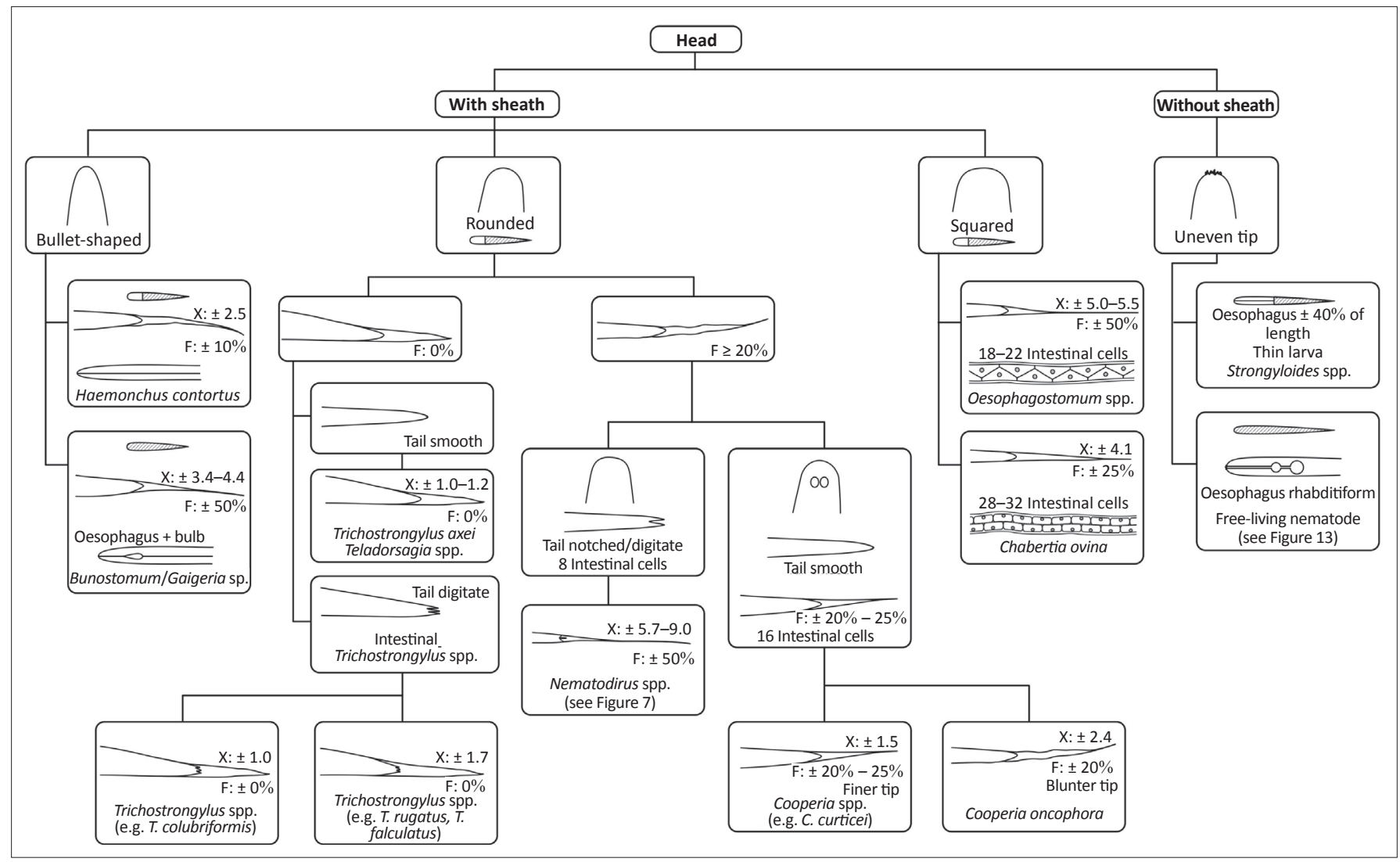

FIGURE 14: Organogram for identifying gastrointestinal nematode and lungworm larvae of small ruminants, including a general description of free-living nematodes. 


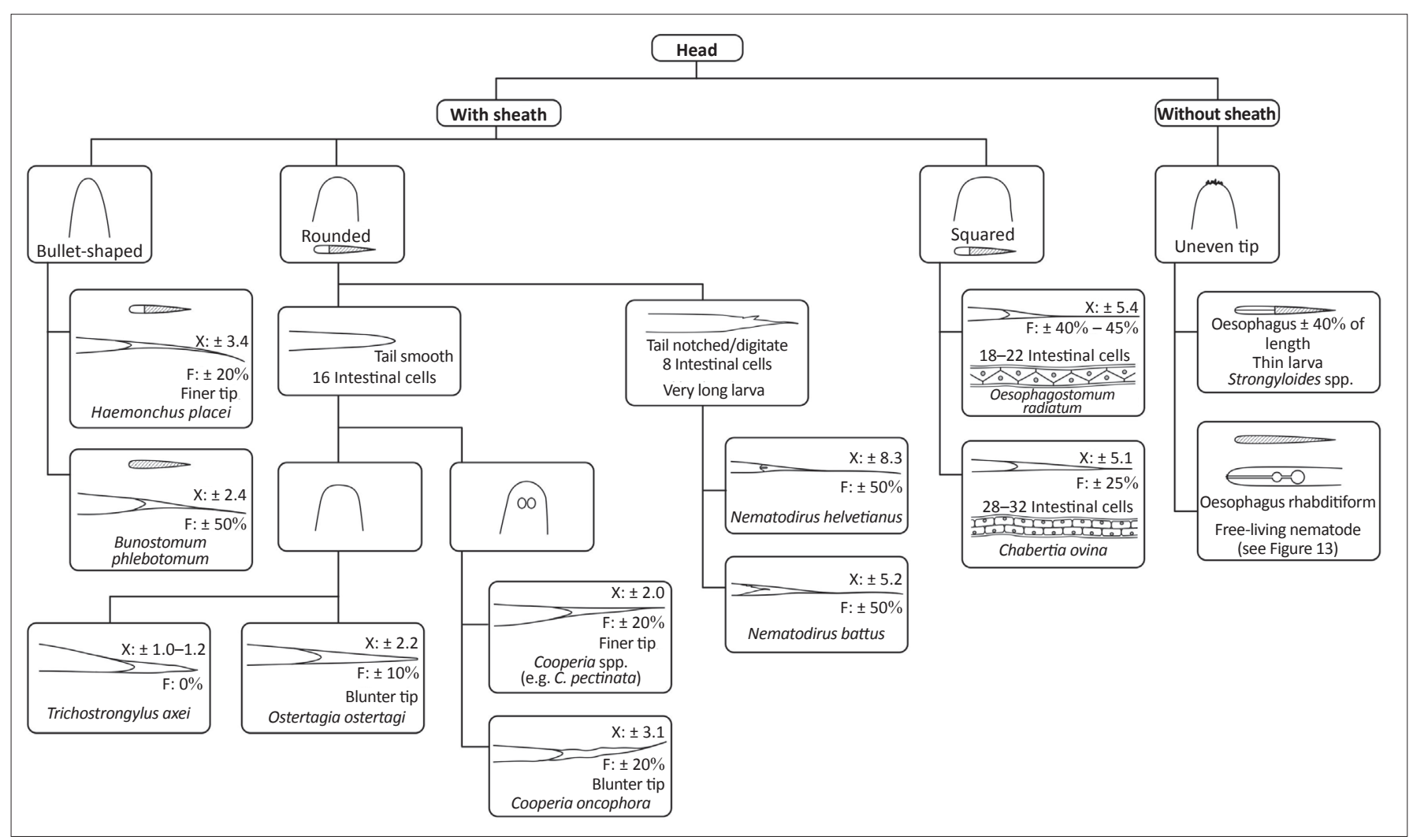

FIGURE 15: Organogram for identifying gastrointestinal nematode and lungworm larvae of cattle.

C. oncophora, but it is important to note that, as mentioned, the STE of the latter is reported to be shorter in small ruminants than in cattle (see above).

\section{The hookworms, Bunostomum spp. and Gaigeria pachyscelis}

Hookworm $\mathrm{L}_{3}$ (B. phlebotomum in cattle, and Bunostomum trigonocephalum and G. pachyscelis in sheep and goats) are characteristically small in size, being almost $100 \mu \mathrm{m}$ less in total length than those of $H$. contortus, the second shortest of the common species or genera. They stain uniformly dark with iodine, in contrast to the $\mathrm{L}_{3}$ of other nematodes that stain light brown cranially and dark brown caudally shortly after addition of the iodine. The STEs vary from 2.4 ' $X$ ' for B. phlebotomum $\mathrm{L}_{3}$ to 4.4 ' $\mathrm{X}$ ' for $\mathrm{G}$. pachyscelis, each with a filament comprising about $50 \%$ of the STE. The oesophagus has a prominent bulb caudally that is most easily observed in the live, active $\mathrm{L}_{3}$, but difficult to visualise after any but very short periods of staining with dilute iodine solution.

The $\mathrm{L}_{3}$ of the following three genera are set apart from the rest by having conspicuously long STEs.

\section{Oesophagostomum spp. and Chabertia ovina}

Helminths of these two genera occur widely disseminated in the world, but Ch. ovina occurs much less commonly than the other. Whilst in small ruminants Oesophagostomum venulosum occurs in Mediterranean-type climate and Oesophagostomum columbianum under warmer subtropical and tropical conditions, in cattle Oesophagostomum radiatum is practically universally disseminated.
A characteristic of the infective larvae of both genera is that they have relatively long STEs (Table 1 and 2). However, note that the filament of $\mathrm{L}_{3}$ of Oesophagostomum spp. has been observed occasionally to break off, resulting in a much different appearance (Mönnig 1931; J. Van Wyk pers. obs., 1996). Whilst apparently not as yet reported for other species, presumably this is also a possibility and should be kept in mind for both Ch. ovina and some others, such as $\mathrm{L}_{3}$ of Nematodirus spp. with long STE filaments. The $\mathrm{L}_{3}$ of Oesophagostomum and Chabertia spp. resemble one another so closely that they are described as practically indistinguishable by some authors. However, much of the confusion appears to have resulted from misidentification in the first place, because the numbers and appearance of the intestinal cells, as well as distinguishing features of the STEs present ready methods of differentiation.

Number of intestinal cells: Whilst, in some instances, both Oesophagostomum and Chabertia genera are described and/or depicted as having 32 rectangular intestinal cells or as being indistinguishable (Anonymous 1977; Eckert 1960; Gibbons et al. 2012), in others where only Oesophagostomum spp. are described, they are listed as having or perhaps having up to 32 cells (Mönnig 1931). In contrast, Dikmans and Andrews (1933) and Borgsteede and Hendriks (1974) correctly describe Ch. ovina to have about 32 and Oesophagostomum spp. about 20 intestinal cells, although the latter authors were uncertain whether some $\mathrm{L}_{3}$ of Oesophagostomum could have up to 32 cells.

Unfortunately it is usually only in the very newly developed infective larvae that the shapes of the intestinal cells are 
clearly discernable, but even if not, it is sometimes possible to count the cells by examining the granular cell content under relatively high magnification. In addition, a further method has been found to illustrate the number of cells per genus very effectively; when exsheathed $\mathrm{L}_{3}$ of Oe. columbianum and Ch. ovina are frozen in liquid nitrogen and subsequently thawed, a bubble can generally be seen in each intestinal cell, very effectively differentiating the two genera (Figures 10 and 11, re-photographed from Van Wyk 1977). The photographs clearly illustrate the difference in numbers of cells, being 18-22 in Oe. columbianum and 28-32 in Ch. ovina.

Intestinal cell shape: The intestinal cells of the $\mathrm{L}_{3}$ of the two genera under discussion also differ dramatically in shape, being triangular in Oesophagostomum spp. and rectangular brick-shaped in Ch. ovina (Figures 4, 10 and 11). However, as discussed, the outlines and thus shapes of the cells are frequently not discernable in any but newly developed larvae.

Sheath tail extension filament: It is in the STE that the most consistent means of differentiation of Oe. columbianum and Ch. ovina $\mathrm{L}_{3}$ lies, not in its length, but mainly in the proportion of the length comprising the filament, being about $50 \%-60 \%$ in the former and $25 \%$ in the latter (Table 1). Hence, despite it being difficult to pinpoint the exact point of inflexion between the filament and the cranial, non-filamentous portion of the STE, the margin of error resulting therefrom is small enough to allow accurate discrimination.

In summary, Oesophagostomum spp. and Ch. ovina $\mathrm{L}_{3}$ respectively have $\pm 18-22$ and 28-32 triangular intestinal cells, the lengths of the STE are \pm 5 ' $X$ ' and $4{ }^{\prime} X$ ' and the filaments constitute from $40 \%$ to $70 \%$ of the STE by species in the former and $25 \%$ in the latter (Figures 5 and 7; Tables 1 and 2).

\section{Nematodirus spp.}

The commonly encountered species are $N$. spathiger, Nematodirus filicollis and Nematodirus abnormalis of small ruminants, Nematodirus helvetianus of cattle and N. battus of lambs and also calves.

When sheathed, Nematodirus spp. $\mathrm{L}_{3}$ are conspicuously longer than those of other nematode genera. They have only eight large intestinal cells, a considerably longer STE (except for $N$. battus) and prominent digital appendages on the tails of the larvae (Figure 3). It is seldom necessary to identify $\mathrm{L}_{3}$ of Nematodirus spp. in routine faecal cultures because the ova of the genus require at least two weeks to hatch, whilst faecal cultures are usually harvested after 5-7 days and require pre-exposure to low temperatures to be able to hatch (Viljoen 1972). However, because Nematodirus ova are much larger than, and hence easily distinguished from, those of most other parasitic nematodes, they can be recorded separately in routine faecal egg counts and any Nematodirus $\mathrm{L}_{3}$ which may be encountered in cultures, are ignored and not included in the differential larval counts. It is important to note, however, that Nematodirus ova can be confused in general appearance with those of M. marshalli, the ova of which are similarly considerably larger than those of most of the parasitic gastrointestinal nematodes (Soulsby 1982). Also, whilst the eggs of the other common Nematodirus species are more or less oval in shape, that of $N$. battus is considerably smaller and much more oblong, resembling 'oversize' eggs of the other common gastrointestinal strongyles.

\section{Strongyloides papillosus}

The $\mathrm{L}_{3}$ of this species are exceptionally thin, the oesophagus comprises about $40 \%$ of the total length, the tip of the tail is bifid and it has no covering second sheath as do the $\mathrm{L}_{3}$ of the other genera, hence also no STE. At the lower magnifications usually used for routine larva identification, it is not possible to see that the tip of the tail is bifid, but it does have the appearance of an STE, of which the tip of the filament has broken off. Misidentification may occur if only the tail of this larva is examined instead of the entire larva, because the disproportionately long oesophagus will be missed and it sometimes seems - mistakenly so - as if it does have an STE.

\section{Dictyocaulus spp.}

Both Dictyocaulus filaria of small ruminants and Dictyocaulus viviparus of cattle are ovo-viviparous. Hence, their ova hatch in their respective hosts and the $L_{1}$ are passed in the faeces. For diagnosis, the $\mathrm{L}_{1}$ are recovered by Baermannisation, otherwise a few faecal pellets or a blob of faeces can be placed in water in a Petri dish and the surrounding water observed under a stereo microscope for larvae migrating out of the faeces.

Dictyocaulus spp. larvae are small in size and very lethargic, the tail ends caudally in a smoothly rounded tip (' $d$ ' in Figure 12), no STE is discernable and the intestinal cells are indistinct and usually brown in colour. A striking difference between $\mathrm{L}_{1}$ of $D$. filaria and $D$. viviparus is a conspicuous bulbous thickening of the sheath on the head of the former that is absent from $D$. viviparus. Similar to the infective larvae of Nematodirus spp., larvae of Dictyocaulus spp. are seldom encountered in representative numbers in routine larval cultures, but for a different reason; they migrate poorly out of such cultures unless collected as described for the recovery of hookworm larvae. Striking photos of D. filaria and D. viviparus larvae can be seen on the website of Gibbons et al. (2012).

\section{Protostrongylid lungworm larvae}

Muellerius, Cystocaulus, Neostrongylus and Protostrongylus spp. are commonly present in sheep faeces in Europe (Cabaret 1986), whilst Varestrongylus pneumonicus, which is found in small ruminants in Asia, is recorded only in roe deer in temperate Europe. The $\mathrm{L}_{1}$ of the protostrongylids are recovered from faeces using a Baermann-derived technique (Cabaret, Dakkak \& Bahaida 1980; also various textbooks, e.g. Hansen \& Perry 1994). The morphology of the tails of some of the larvae is shown in Figure 12, but persons who 
encounter these $\mathrm{L}_{1}$ more commonly should study the more detailed descriptions in Van Wyk et al. (2004) and Gibbons et al. (2012).

\section{Free-living nematodes}

Cultures of faeces picked up from the ground are often contaminated with free-living nematodes, which then tend to dominate faecal cultures to the extent that it is almost impossible to do a differential parasitic nematode larval count. Thus it is preferable to collect faeces from the rectum for cultures, or from bags hung on the animal, although contamination has also been described despite the use of faecal collecting bags (Van Wyk et al. 2004), in which case it was overcome by shearing and thoroughly washing the buttocks of the animals.

It is important to note that, even though they often resemble the $\mathrm{L}_{3}$ of parasitic nematodes, most of the free-living nematodes encountered in faecal cultures are adults and not larvae. In contrast with the majority of the parasitic larvae, the commonly encountered free-living nematodes stain uniformly, extremely dark brown with iodine, are relatively thick and cigar-shaped, have a rhabditiform oesophagus (i.e. with two conspicuous bulbs caudally) and a long tail with no covering sheath. However, the genera differ markedly from one another (as briefly indicated by Van Wyk et al. 2004) and these nematodes differ to such an extent from the parasitic larvae that there should seldom be confusion.

\section{Conclusion}

There are dwindling numbers of persons trained in 'conventional' helminthological techniques, such as larva identification, which is relatively difficult to learn even when persons with the required skill are available as mentors to the inexperienced. In addition, whilst the full range of pure cultures (and thus larvae) of the common gastrointestinal nematodes of both sheep and cattle were generally available previously, few laboratories maintain these any longer. Thus, it is essential that every possible aid, such as the newly described use of the proportion of the STE in identification, be available to those who need to learn to differentiate infective larvae obtained by faecal culture.

\section{Acknowledgements}

This work was supported by the EU 'PARASOL' (EU-FP6) and 'RISC-NET' projects, the latter under the 'CIDLID' call for applications, funded by a partnership between the Biotechnology and Biological Sciences Research Council, the Department for International Development and the Scottish Government.

Hennie Gerber (now deceased) maintained pure nematode cultures and Lynne Michael and Regina Alves were instrumental in preparations. Jacques Cabaret was the source of information on lungworm larvae, which are described in more detail in Van Wyk et al. (2004). Ian Carmichael went to much trouble to locate original material from trials of
Beveridge, Martin and Pullman (1985). Michael O'Callaghan drew the ' $f$ ' diagram in Figure 3. Hervé Mauleon helped with descriptions of free-living nematodes. Ron Kaminsky, Frank Jackson, Jacques Cabaret, Jacques Cortet, Eric Morgan and Flip van Schalkwyk supplied $\mathrm{L}_{3}$ of a variety of species.

\section{Competing interests}

The authors declare that they have no financial or personal relationships which may have inappropriately influenced them in writing this article.

\section{Authors' contributions}

J.A.v.W. (University of Pretoria) was responsible for developing thenovelapproach to morphologicalidentification of infective larvae of the common gastrointestinal nematode genera of small ruminants and cattle and wrote the manuscript. E.M. (University of Pretoria) was responsible for all the art work and finishing of the article.

\section{References}

Anonymous, 1977, 'Examination and identification of third-stage larvae of nematodes and of the immature stages of trematodes in the snail', Manual of Veterinary Parasitological Laboratory Techniques, Reference Book 418, 36-39, Ministry of Agriculture, Fisheries and Food, London.

Beveridge, I., Martin, R.R. \& Pullman, A.L., 1985, 'Development of the parasitic stages of Nematodirus abnormalis in experimentally infected sheep and associated pathology', Proceedings of the Helminthological Society of Washington 52 , 119-131.

Boch, J. \& Supperer, R., 1983, Veterinärmedizinische Parasitologie, Paul Parey, Berlin.

Boev, S.N., 1984, 'Protostrongylids', Fundamentals of Nematology 25, Oxonian Press, New Delhi.

Borgsteede, F.H.M. \& Hendriks, J., 1974, 'Identification of infective larvae of gastrointestinal nematodes in cattle', Tijdschrift Diergeneeskunde 99, 103-113.

Cabaret, J., 1986, Répartition géographique des protostrongylidés des ovins. Fréquence et importance de cette parasitose pulmonaire en Europe et en Afrique du Nord [Geographical distribution of protostrongylids. Frequency and importance of this lung parasitosis in Europe and North Africa]. Épidémiologie et Santé Animale 10, 61-72.

Cabaret, J., Dakkak, A. \& Bahaida, B., 1980, 'A technique for the evaluation of the number of lungworm first stage larvae in sheep faeces', British Veterinary Journal 136, 296-298. PMid:7388593

Christie, M. \& Jackson, F., 1982, 'Specific identification of strongyle eggs in small samples of sheep faeces', Research in Veterinary Science 32, 113-117. PMid:7201151

Corticelli, B. \& Lai, M., 1964, La diagnosi di tipo d'infestione nella strongilosi gastrointestinale del bovino in Sardegna con le larve infestive [Diagnosis of the infestation type in gastro-intestinal strongylosis of cattle in Sardinia by differentiation of the type in gastro-intestinal strongylosis of cattle in Sardina
infective larvae]. Veterinaria Italiana 15, 190-213.

Dikmans, G. \& Andrews, J.S., 1933, 'A comparative morphological study of the infective larvae of the common nematodes parasitic in the alimentary tract of sheep', Transactions of the American Microscopical Society 52,1-25. http:// sheep, Transactions of the
dx.doi.org/10.2307/3222221

Eckert, J., 1960, Die Diagnose des Magen-Darmstrongyliden Befalles des Schafes durch Differenzierung der freilebenden dritten Larven [Diagnosis of gastro-intestinal worms in sheep by differentiation of the free-living third-stage larvae]. Zentralblatt Für Veterinärmedizin 7, 612-630. http://dx.doi.org/10.1111/j.1439-0442.1960. tb00274.x

Gibbons, L.M., Jacobs, D.E., Fox, M.T. \& Hansen, J., 2012, 'The RVC/FAO guide to veterinary diagnostic parasitology. Faecal examination of farm animals for helminth parasites', viewed 19 October 2012, from http://www.rvc.ac.uk/review/ helminth parasites', viewed 19
Parasitology/Index/Index.htm

Hansen, J. \& Perry, B., 1994, The epidemiology, diagnosis and control of helminth parasites of ruminants, pp. 83-90, International Laboratory on Animal Diseases, Nairobi.

Hansen, M.F. \& Shivnani, G.A., 1956, 'Comparative morphology of infective nematode larvae of Kansas beef cattle and its use in estimating incidence of nematodiasis in cattle', Transactions of the American Microscopical Society 75, 91-102. http:// in cattle', Transactions of the Am
dx.doi.org/10.2307/3223659

Henriksen, S.A., 1972, Undersogelser verdrorende lobe-tarmstrongylider hos kvaeg. I. Nogle forelobige erfaringer med $\mathrm{L}_{\text {-analyser [Investigations concerning }}$ bovine gastro-intestinal strongyles. I. Preliminary results of $L_{3}$ analyses]. Nordisk Veterinaer Medicin 24, 49-55. PMid:4666546 
Keith, R.K., 1953, 'The differentiation of the infective larvae of some common nematode parasites of cattle', Australian Journal of Zoology 1, 223-235. http:// nematode parasites of cattle',
dx.doi.org/10.1071/ZO

Lancaster, M.B. \& Hong, C., 1987, 'Differentiation of third stage larvae of "ovine Ostertagia" type and Trichostrongylus species', The Veterinary Record 120, 503. http://dx.doi.org/10.1136/vr.120.21.503, PMid:3604011

Malan, F.S. \& Visser, P.S., 1993, 'Faecal egg counts by a new method using tube filters', Proceedings of the 14th International Conference of the World Association for the Advancement of Veterinary Parasitology (WAAVP), Cambridge, UK, 08-13 August 1993, p. 328.

McMurtry, L.W., Donaghy, M.J., Vlassoff, A. \& Douch, P.G.C., 2000, 'Distinguishing morphological features of the third larval stage of ovine Trichostrongylus spp.', Veterinary Parasitology 90, 73-81. http://dx.doi.org/10.1016/S03044017(00)00230-2

Mönnig, H.O., 1931, 'The specific diagnosis of nematode infestation in sheep', 17 th Annual Report of the Director of Veterinary Services and Animal Industry, Onderstepoort, Pretoria, Union of South Africa, pp. 255-264.

O'Callaghan, M.G., 2004, 'Observations on the sheath extension of the third stage, infective larvae of Trichostrongylus rugatus', Veterinary Parasitology 126, 397-402. http://dx.doi.org/10.1016/j.vetpar.2004.07.027, PMid:15567044
Reinecke, R.K., 1973, 'The larval anthelmintic test in ruminants', Technical Communication 106, Department of Agricultural Technical Services, Pretoria.

Roberts, F.H.S. \& O'Sullivan, P.J., 1950, 'Methods for egg counts and larval cultures for strongyles infesting the gastrointestinal tract of cattle', Australian Journal of Agricultural Research 1, 99-102. http://dx.doi.org/10.1071/AR9500099

Rossanigo, C.E. \& Gruner, L., 1996, 'The length of strongylid nematode infective larvae as a reflection of developmental conditions in faeces and consequence on their viability', Parasitology Research 82, 304-311. http://dx.doi.org/10.1007/ s004360050118, PMid:8740545

Soulsby, E.J.L., 1982, 'Helminths, arthropods and protozoa of domesticated animals', Ballière Tindall, London.

Van Wyk, J.A., 1977, 'A rapid method for differentiating between the infective larvae of Oesophagostomum columbianum and Chabertia ovina', Onderstepoort Journal of Veterinary Research 44, 197-199. PMid:614536

Van Wyk, J.A., Cabaret, J. \& Michael, L.M., 2004, 'Morphological identification of nematodes of small ruminants and cattle simplified', Veterinary Parasitology 119, 277-306. http://dx.doi.org/10.1016/j.vetpar.2003.11.012, PMid:15154594

Viljoen, J.H., 1972, 'Morphology of the free-living stages of Nematodirus species with some observations on their development under laboratory conditions', Journal of the South African Veterinary Association 43, 87-94. PMid:4680366 